\title{
Measuring self-care in patients with heart failure: A review of the psychometric properties of the European Heart Failure Self-Care Behaviour Scale (EHFScBS)
}

Natasa Sedlar, Gregor Socan, J erneja Farkas, J an Martensson, Anna Strömberg, Tiny J aarsma and Mitja Lainscak

The self-archived postprint version of this journal article is available at Linköping University Institutional Repository (DiVA):

http:// urn.kb.se/ resolve?urn=urn:nbn:se:liu:diva-139613

N.B.: When citing this work, cite the original publication.

Sedlar, N., Socan, G., Farkas, J ., Martensson, J., Strömberg, A., J aarsma, T., Lainscak, M., (2017), Measuring self-care in patients with heart failure: A review of the psychometric properties of the European Heart Failure Self-Care Behaviour Scale (EHFScBS), Patient Education and Counseling, 100(7), 1304-1313. https:/ / doi.org/ 10.1016/j.pec.2017.02.005

Original publication available at:

https:// doi.org/ 10.1016/j.pec.2017.02.005

Copyright: Elsevier: 12 months http://www.elsevier.com/

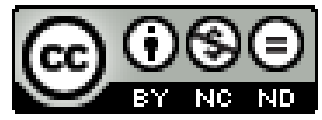


Review

Measuring self-care in patients with heart failure: A review of the psychometric properties of the European Heart Failure SelfCare Behaviour Scale (EHFScBS)

\author{
Natasa Sedlar ${ }^{\mathrm{a}^{*}}$, Gregor Socan ${ }^{\mathrm{b}}$, Jerneja Farkas ${ }^{\mathrm{a}, \mathrm{c}}$, Jan Mårtensson ${ }^{\mathrm{d}}$, Anna \\ Strömberg ${ }^{\mathrm{e}, \mathrm{f}}$, Tiny Jaarsmag ${ }^{\mathrm{g}, \mathrm{h}}$ and Mitja Lainscak ${ }^{\mathrm{i}, \mathrm{j}}$
}

\footnotetext{
Affiliations

${ }^{a}$ National Institute of Public Health, Slovenia

${ }^{\mathrm{b}}$ Department of psychology, University of Ljubljana, Slovenia

c Department of Research, General Hospital Murska Sobota, Slovenia

${ }^{\mathrm{d}}$ Department of Nursing, Jönköping University, Sweden

e Department of Medical and Health Sciences, Linköping University, Sweden

${ }^{\mathrm{f}}$ Department of Cardiology, Linköping University, Sweden

${ }^{\mathrm{g}}$ Department of Social and Welfare Studies, Linköping University, Sweden

${ }^{\mathrm{h}}$ Mary MacKillop Institute for Health Research, Australian Catholic University, Australia

i Department of Internal Medicine, General Hospital Murska Sobota, Slovenia

${ }^{\mathrm{j}}$ Faculty of Medicine, University of Ljubljana, Slovenia

* Corresponding author at: National Institute of Public health, Zaloska cesta 29, SI-1000 Ljubljana, Slovenia. Tel.: +386 15205 776; E-mail address: natasa.sedlar@nijz.si
} 


\section{ABSTRACT}

Objective: The aim of this study was to review and evaluate the evidence related to psychometric properties of the European Heart Failure Self-Care Behaviour Scale (EHFScBS) that was developed and tested to measure health maintenance behaviours of heart failure (HF) patients and translated into several languages.

Methods: PRISMA guidelines were used to search major health databases (PubMed, Scopus and ScienceDirect), to identify relevant studies. A literature search was undertaken in November 2015. An integrative review, aiming to bring together all evidence relating to the psychometric properties (validity, reliability) of the EHFScBS was conducted.

Results: 13 eligible studies were included. The results showed content, discriminant and convergent validity of the 9- and 12-item scale across the samples, while the factor structure of both versions of the scale was inconsistent. Most commonly used reliability estimates (Cronbach's alpha) of the total scale were satisfactory.

Conclusion: Overall, published data demonstrate satisfactory psychometric properties of the EHFScBS, indicating that the scale is a reliable and valid tool for measuring health maintenance behaviours of HF patients.

Practice implications: Taking the findings regarding the factorial structure of the scale into account, we recommend the use of the total EHFScBS score or scores on specific items.

\section{Keywords}

Self-care behaviour, EHFScBS, adaptation, validation, systematic review 


\section{Introduction}

A growing body of evidence shows the importance of the appropriate heart failure (HF) selfcare in both preventing serious complications and consequences of $\mathrm{HF}$ as well as in achieving positive health outcomes (e.g. improved survival [1], less frequent hospital admissions and emergency department visits, higher quality of life [2,3]).

In order to evaluate patients' self-care behaviour and the impact of educational interventions aiming to promote HF self-care, reliable and valid research instruments are needed. So far, the European Heart Failure Self-care Behaviour Scale (EHFScBS) [4] and the Self-Care of Heart Failure Index v.6.2 (SCHFI v.6.2) [5, 6] are among the most commonly used assessment instruments. Moreover, they are the only two instruments that have been demonstrated to be valid and reliable but the conceptualization of the HF self-care between the two instruments seems to be different [6].

This review focuses on the EHFScBS that was developed and tested in 2003 by Jaarsma et al. [4], to measure behaviours that HF patients perform to maintain life, healthy functioning and wellbeing. Three dimensions of health maintenance behaviours were hypothesized within the 12-item scale (Complying with regimen, Asking for help and Adapting activities) but were only partially confirmed in the original study. Further studies examining the psychometric properties

of the scale (e.g. Baydemir et al. [7], Shouldham et al.[8], Yu et al. [9]) suggested other factor solutions. The scale was translated and used in several countries and was reported to be easy to administer and is free of charge.

In 2009 the scale was further tested in pooled sample of 2592 patients from six countries [10]. Based on the improvement of confirmatory factor analysis (CFA) goodness-of-fit indices of a single and a two factor model and more satisfactory reliability estimates, the scale was reduced 
to nine items (EHFScBS-9); the reduced version showed better construct validity and reliability, but a two factor solution (Consulting behaviours, Adherence to regimen) had low internal consistency of the second factor. Findings of further validation studies (e.g. United States [11]. Germany [12], Italy [13], Greece [14]) however have reported different factorial solutions of the scale.

Summarizing, the factorial structure of translated scales across the samples is not consistent with the exception of the consulting behaviour factor which was recognized in all of the studies. Also, in several studies the internal consistency of the EHFScBS subscales was not adequate. In the light of this, we believe it is relevant to review and critically evaluate findings of these studies. Therefore the aim of this study is to bring together and re-examine evidence relating to the psychometric properties of the twelve and nine-item version of the EHFScBS.

\section{Methods}

\subsection{Selection criteria}

Studies were included in the systematic review if they (i) included measures of HF selfcare: the EHFScBS-12 or the EHFScBS-9; (ii) recruited patients with HF; (iii) aimed to examine the psychometric properties of the questionnaire (iv) published full reports in English language.

\subsection{Search methods and selection of studies}

Our study was conducted according to the PRISMA guidelines [15]. Articles were obtained by searching electronic bibliographic databases PubMed, Scopus and ScienceDirect for the period between June 9, 2003 (when the EHFScBS-12 was first published) and November 1, 
2015 using search terms: “Self-care” OR “self-care behaviour” OR “self-care behavior” OR “European Heart Failure Self-care Behaviour Scale” OR “EHFScBS” OR “EHFScBS-9” AND “chronic heart failure" OR "heart failure". Alternative searches were conducted on Google Scholar, contacts with experts and hand searching reference lists of relevant articles.

\subsection{Data collection}

Obtained papers were initially screened based on the title an abstract. In the next phase, all relevant articles were retrieved in full-text and reviewed by two reviewers (NS, JF); disagreements were resolved through discussion or by consulting a third reviewer (ML).

A predesigned data extraction form was used to gather information on the study design (a version and language of the questionnaire), participant characteristics (age, gender, NYHA - New York Heart Association classification; LVEF - left ventricular ejection fraction of participants) and the characteristics of the self-care questionnaire (a mean self-care score, an item with lowest/highest score, construct, criterion and concurrent validity, stability and homogeneity of the questionnaire).

\subsection{Assessment of risk of bias}

Two independent reviewers (NS, GS) assessed a risk of bias in individual studies by using the risk of bias tool for observational studies from the Agency for Health care Research and Quality (the revised RTI Item Bank to Assess Risk of Bias and Precision) [16]. Disagreements between reviewers were resolved by discussion or consultation with a third reviewer (ML).

For the scope of this review six items were used to assess selection, performance, detection and reporting bias. Based on the assessment across key domains, each of the studies 
was rated as having a low, medium or high overall risk of bias; in order to be labelled as of a low risk of bias, the study should not have any key domains rated as negative or not more than two key domains rated as unclear. Precision was assessed separately with one item.

\subsection{Data analysis}

An integrative review, aiming to bring together all evidence relating to the psychometric properties of the EHFScBS was conducted. The criteria for evaluating the psychometric properties of the EHFScBS were arbitrarily set, covering some of the most common measures of validity and reliability.

\subsubsection{Validity}

Content validity of the scale was reported for the original EHFScBS-9 and the EHFScBS12 scale $[4,10]$ and for some translated versions of the scale $[9,17]$. Based on this findings no major threats to content validity were observed as the scale includes construct-relevant content and items that represent the measured concept. Therefore content validity was not further investigated in this study.

In order to estimate the fit indices of confirmatory factor analysis the following cut-off values were used: RMSEA (<.06); CFI (>.95), NFI ( $\geq .95)$; NNFI(TLI) ( $\geq .095)$; SRMR (>.80); (according to $\mathrm{Hu}$ and Bentler [18]); WRMR (<.90) (according to Muthen and Muthen [19]). Fit indices GFI and AGFI were not considered in the analysis because they had been found (e.g. [20]) to be affected by the sample size, and therefore their appropriate cut-off is difficult to determine. 
With respect to the minimum sample size recommendations for exploratory factor analysis provided by Mundfrom et al. [21] and the data properties (expected low to wide communalities, three factors, three or four variables per factor, respectively), we considered only the factor analysis results from studies that included at least 100 participants.

In order to evaluate convergent and discriminant validity (the first requires positive correlations between measures of similar constructs, whereas the latter requires low correlations for measures of unrelated constructs, or negative correlations for related but opposite constructs [22]), strength of correlations was interpreted according to Cohen's table of effect size magnitudes [23]; a correlation coefficient from .10 to .30 indicates small to medium association, values between .30 and .50 moderate association and values of .50 or larger strong association. Another aspect of validity requires difference in the HF self-care scores between two groups of patients that are expected to have different scores (contrasted groups, i.e. groups of patients who had or had not received education); this was interpreted according to the statistical significance of between group differences.

A conventional statistical significance level $(p<.05)$ was considered.

\subsubsection{Reliability}

Test-retest reliability was assessed by intraclass correlation coefficient (ICC) and weighted Kappa coefficient. For the purpose of this study a rule of thumb suggested by Landis and Koch [24] (originally proposed for interpretation of Kappa, ICC is interpreted similarly) was used; according to them values .40 to .59 indicate moderate, .60 to .79 substantial, and .80 outstanding test-retest reliability. 
Discrimination power in measuring the concept of the HF-related self-care was evaluated by examining corrected item-total correlation, with values above the criterion level of .30 indicating acceptable discrimination power [25]. Internal consistency was further evaluated by Cronbach's alpha coefficient; according to Nunnally and Bernstein [25]; values larger than .80 have appropriate reliability for group-level analyses, and values over .70 have modest reliability.

\section{Results}

\subsection{Included studies}

The electronic database searches resulted in 2154 records (PubMed $n=621$, Scopus $n=1295$ and ScienceDirect $n=238$ ). After removal of duplicates, this resulted in 1431 records. An additional 1357 records were excluded after initial screening based on the title and abstract. This resulted in total of 74 studies using the EHFScBS that were retrieved and reviewed in full text. Thirteen studies fulfilled the inclusion criteria. PRISMA flow diagram shows the selection of papers for inclusion and exclusion (Figure 1).

The included studies were cross sectional studies; nine of them investigated the psychometric properties of the EHFScBS-12 [4,7-10,17,26-28] and five of the EHFScBS-9 [10$14]$.

The twelve-item scale has been validated in several languages; Jaarsma at al. [4] used pooled data of patients from Sweden, the Netherlands and Italy, later on validation studies of English [8], Japanese [17], Italian [27], Chinese [9], Brazilian Portuguese [26], Turkish [7] and Polish [28] versions of the scale were published. Psychometric properties of the nine-item scale 
were first tested in a pooled convenience sample of patients from Sweden, the Netherlands, the United Kingdom, Italy, Germany and Spain [10]; afterwards validation studies of German [12], English [11], Greek [14] and Italian [13] versions were published.

Studies were undertaken in a range of settings (hospitals, outpatient clinics, primary care, other); however, most commonly in hospitals and outpatient clinics. Sample sizes ranged from 93 to 2592 . Mean ages ranged from 57 to 78 years; the percentage of men ranged from $38 \%$ to $78 \%$; NYHA of included patients ranged from I to IV; mean LVEF(\%) ranged from $29 \%$ to $54 \%$ but was not assessed in four of the included studies (Table 1).

\subsection{HF Self-care score}

Mean score of the scale ranged from 24 to 34 on the EHFScBS-12 (possible score range from 12 to 60 ) and from 18 to 24 on the EHFScBS-9 (possible score range from 9 to 45), with lower scores indicating better HF self-care. For both versions of the scale, most frequently performed self-care behaviour was 'taking medications as prescribed', whereas the less frequent self-care behaviours were various: 'exercising regularly', 'contacting provider in case of weight gaining' 'weighting every day', 'limiting the amount of fluids' and 'eating a low-salt diet' (Table 2).

\subsection{Psychometric properties of the EHFScBS-12}

\subsubsection{Validity}

Three factors were originally hypothesized within the 12-item scale: Complying with regimen, Asking for help and Adapting activities. However, this was only partially confirmed by 
Jaarsma et al. [10] as a three-factor model in CFA showed only slightly better fit than a singlefactor model (Table 3). Also, only some fit indices supported the proposed three factor CFA structure in the study by Yu et al. [9]; therefore authors proposed two principal components (Help seeking, Regimen-complying behaviours) explaining 31\% of the variance. Regarding a single factor model, marginally acceptable fit of the EHFScBS single scale was obtained by CFA in the study evaluating Japanese version of the EHFScBS [17]. On the contrary, PCA based four component solution (Compliance to the treatment, Adherence to the activities, Adherence to the recommendations, Getting help) explaining 61\% of variance was proposed by Baydemir et al. [7]. The solution was further confirmed by CFA, but the reasons for the use of an exploratory approach in the first place were not clearly stated. Moreover, reliability coefficients (Cronbach's alpha) for the third and fourth factor were extremely low (alpha F3=.12; alpha F4=.28), indicating a limited psychometric usefulness of the proposed scales. In a similar manner, exploratory approach was adopted by Shuldham et al. [8], who also identified four principal components explaining 59\% of variance, but reported problems with identifying proposed themes.

Convergent validity of the 12-item scale was examined in three studies; weak support was provided in two studies (statistically significant (small/marginally modest) correlations of the scale and: HF Compliance questionnaire $(r=.32 ; p<.001)$ [10] and subscale of SCAQ (Self-Care Agency Questionnaire) $(r=-.29 ; p<.05)$ [17]), while it was not supported in one study [8], (low and non-significant $(r=.09 ; p=.25)$ association of the scale and SCHFI). On the contrary, discriminant validity of the scale was supported in three studies (Jaarsma et al. [10], Pulignano et al. [27], Shouldham et al. [8]) through hypothesised low and non-significant correlations between scores obtained from the EHFScBS-12 and the health-related quality of life measure for HF the MLwHFQ (Minnesota Living with Heart Failure Questionnaire). 
Results in one study showed significant better $(p<.001)$ HF self-care in patients that previously received structured HF education than in patients before enrolment in the heart failure clinic [27]. The results of another study [4] showed non-significant difference $(t=2.6 ; p=.09)$ in HF self-care between patients with standard and extra care.

\subsubsection{Reliability}

Test-retest reliability was assessed in three studies. Feijó et al. [26] reported good levels of stability obtained by ICC, but results were obtained in a rather small sample. Kato et al. [17] reported low to good test-retest reliability on an item level, while Shuldham et al. [8] reported good test-retest stability with no statistically significant differences in item scores on retesting.

All corrected item-total correlations exceeded the accepted cut-off of .30 [25] only in one study [4].

Reliability coefficients for the total scale were satisfactory (modest to appropriate) with values of Cronbach's alpha around .70 and .80, except for one study [28] reporting slightly lower values (.64) (Figure 2). Five studies reported Cronbach’s alpha if item deleted; altogether, only a few of the obtained values slightly exceeded the alpha of the whole scale. However, reliability coefficients of proposed subscales were reported only in the Turkish validation study [7], where two subscales had lower than regularly accepted levels.

\subsection{Psychometric properties of the EHFScBS-9}

\subsubsection{Validity}

The constructor of the scale [10] proposed a two-factor solution (Consulting behaviours, Adherence to regimen) of the nine-item scale due to its slightly better fit indices compared to a 
single factor solution; however, the factor Adherence to regimen showed a relatively low reliability coefficient (Cronbach’s alpha=.56) (Table 4). Further studies did not replicate findings regarding the proposed two-factor solution. Köberich et al. [12] adopted an exploratory approach and reported a three-component solution; however, only one of the obtained components could be conceptualized as the subscale (Asking for help) and reasons for the use of PCA were not stated. Exploratory approach was adopted by Lambrinou et al. [14] as well, following ambiguous findings regarding the fit of a one-factor and a two-factor model. The initial PCA threecomponent solution (Adhering to recommendation, Fluid and sodium management, Physical activity and recognition of deteriorating symptoms) was further verified with CFA but showed rather low internal consistency (Cronbach's alpha .57, .54 and .51, respectively) and low correlations between the estimated factor scores and the true values of factors (FSDC .57, .75, .62). Likewise, Vellone et al. [13] confirmed a three-factor model (Consulting behaviours, Autonomous-based adherence, Provider-based adherence) using CFA. Cronbach's alpha coefficients for the subscales were not reported, whereas FSDC (.82, .95, .77, respectively) were satisfactory. On the contrary, Lee et al. [11] performed CFA and confirmed acceptable fit of the EHFScBS single scale and the subscale Consulting behaviour.

Results partially supported the convergent validity of the nine-item scale in two studies (statistically significant moderate correlations of the scale and the HF Compliance questionnaire $(r=.37 ; p<.001)$ [10] and subscales of the SCHFI $(r=-.59 ; r=-.42 ; p<.01)[11])$. And discriminant validity was supported in four studies through hypothesised not statistically significant correlations of the scale and the measures of health-related quality of life in patients with HF the KCCQ (Kansas City Cardiomyopathy Questionnaire) [12] and the MLWHFQ [10,11,14]. 
Statistically significant differences between patients who had or had not received patient education were shown in one study $(t=2.11 ; p<.05)$ [12]; but the sample size of patients with extra care was very small $(N=19)$.

\subsubsection{Reliability}

Test-retest reliability was reported only in one study [12] where substantial ICC of the scale and moderate to substantial ICC on an item level were reported.

Three studies reported corrected item-total correlations of the nine-item scale. However, only two of them [10,11] reported the results on an item level. Item 'taking medication as prescribed' did not exceed the accepted cut-off .30 [25] in both of the studies and therefore seemed not very satisfactory from a psychometric perspective.

The reliability coefficients for the total scale were satisfactory (modest to appropriate) with values exceeding .70 and also reaching .80; slightly lower level was obtained in the study by Lambrinou et al. [14] (.66) (Figure 2). On the contrary, reliability of subscales measured by coefficient alpha was not satisfactory in the study by Jaarsma et al. [10] (Cronbach's alpha of the subscale Adherence to regimen .56) and the study by Lambrinou et al. [14] (all three subscales; Cronbach's alpha .57, .54, .51). The use of FSDC gave satisfactory internal consistency in the study by Vellone et al. [13].

\subsection{Risk of bias of included studies}

The overall risk of bias of the included studies was either low or medium (Appendix 1). All together five studies failed to provide sufficient information to assess selection bias $[4,10,11,13,27]$ (either failed to provide details on inclusion/exclusion criteria and/or details on 
strategy for recruiting participants); in case of Jaarsma et al. $[4,10]$ this was due to the use of a pooled convenience sample of patients from different sites. We assumed that all studies except two $[4,10]$ that failed to provide adequate information, were free of performance bias. However this assessment is mostly based on the descriptions in methods sections of the studies where authors in general rarely report deviations from the protocol, so this should be interpreted with caution. All studies were assessed to be free of detection bias as reliable and valid measures were used. 21 official versions of the EHFScBS scale are available that have been translated and back translated following a standard procedure [29]. In some of the included studies a process of translation and adaptation of the scale (Brasilian Portugues [26], Japanese [17], Italian[27], Polish [28], Chinese [9] and Greek [14]) was also described in more detail. Regarding the clinical data, most of the studies combined self-reported data with objective measures (e.g. medical records, lab findings); however details on that were not clearly stated in some studies, whereas two studies [7,9] used only the questionnaire for the participants. All studies were assessed to be free of reporting bias as outcomes outlined in abstract and protocol were reported in the results and potential unplanned analyses seemed appropriate. In order to be free of the risk of bias related to precision at least one measure of validity and one measure of reliability had to be used; two studies [26,28] failed to reach this criteria.

\section{Discussion and conclusion}

\subsection{Discussion}

To our knowledge this is the first systematic review that aimed to evaluate evidence relating to the psychometric properties of both the EHFScBS-12 and the EHFScBS-9 questionnaire. Nine

of the included studies investigated the psychometric properties of the twelve-item version and 
five of them focused on the reduced nine-item version, therefore more solid conclusions can be drawn for the longer version. All of the included studies used cross-sectional data. The sample sizes to perform factor analysis appeared to be adequate in most of the studies.

Testing the factorial structure of the scale presents an important step in validating the concept being measured. Originally, three factors were hypothesized within the 12-item scale [4] and a two-factor solution was proposed for the nine-item version of the scale [10]. However, most of the further studies testing the construct validity of the scale (by the means of CFA, EFA or PCA) have not confirmed this, leading to the conclusion that the factorial structure of the scale across the samples is non-consistent. The consulting behaviour factor, however, was recognized in all of the studies.

CFA is generally used to verify the proposed factor structure of the scale and as such it is accepted as the primary tool. This was not thoroughly applied in the literature which further complicates the interpretation on the factorial structure. Using CFA prior to exploratory approaches is important as it could give some further insights in the nature of the measured concept. Discussing possible reasons for obtained unsatisfactory fit indices in CFA could for example help with identification of items that do not function well/ issues with translation of the scale/ cultural differences or possible different conceptualizations of HF self-care. Only then an exploratory approach aiming to find a model that fit the data should be adopted.

With more items, it is generally possible to better determine the nature of the underlying construct. Therefore we should note the factor-to-variable ratio ie. the number of items per factor that should be included in the scale. The ratio 1:3, that was obtained in some of the included studies [7,8,12-14] is considered to be the smallest acceptable ratio [30]. In other words another reduction of the scale would imply the use of a single EHFScBS score or scores for two subscales at most. 
The aspect of convergent and discriminant validity of the EHFScBS-12 and the EHFScBS-9 has been investigated in several studies. Most of the evidence supports discriminant validity of the scale through its low associations with measures of the health-related quality of life in HF patients. On the other hand results support convergent validity of the scale through its small/moderate associations with measures of similar constructs (an adherence instrument (revised HF Compliance questionnaire; $r=0.32 / 0.37$ ) [10], Self-care agency questionnaire $(r=-0.29)$ [17], subscales of SCHFI Maintenance and Management $(r=-0.59, r=-0.42)[11])$. However, convergent validity was not supported in one study [8], where association with SCHFI was low and non-significant ( $r=.09 ; p=.25)$ but according to Cameron et al. [6] this could be due to the use of the index score on the SCHFI (consisting of self-care maintenance, management, and confidence subscales) that is no longer recommended.

\subsubsection{Limitation of the studies}

One of the most important limitations of this review is restricted generalizability of the findings due to the use of inconsistent methodology across studies and relatively low proportion of studies that included psychometric analysis of the scale. Thus, empirical findings published to date do not allow us to draw conclusions about the specific language version of the scale that performed best.

Moreover, this review includes articles published in English language up to November 1 2015, so it is possible that some relevant studies published afterwards are missing. Also, articles mentioning validation of the scale that had other primary aims were not included in this review. It is also possible that the psychometric properties of the translated scales have been more rigorously tested in the process of development, but details on that were not reported in the published articles. 


\subsection{Conclusion}

EHFScBS is valid and reliable tool for measuring health maintenance behaviours of HF patients. Published data demonstrate satisfactory psychometric properties (content, discriminant, convergent validity and reliability) of the translated versions of the 9- and 12- item scale. Regarding construct validity, the consulting behaviour factor was recognized in all of the studies. However, the factor structure of both versions of the scale was inconsistent across samples, and should therefore be addressed in further studies.

\section{3. $\quad$ Practice implications}

It is important that the instrument for measuring HF self-care is valid and reliable if conclusions should be the basis for educational and counselling interventions. The EHFScBS demonstrated satisfactory psychometric properties, but it is likely that the total EHFScBS score or subscale scores are less informative and helpful than the scores on specific HF self-care behaviours.

Moreover, we believe that the next step in the development of the questionnaire would be testing the ability of the EHFScBS to predict HF self-care behaviours in patients. That would be of great relevance as it could further support clinical application of the scale and guide interventions for clinical practice. 


\section{Role of funding}

The authors acknowledge the project [Heart failure epidemiology in Slovenia: prevalence, hospitalizations and mortality, J3-7405] was financially supported by the Slovenian Research Agency.

\section{Conflict of interest}

None declared.

\section{Acknowledgements}

None. 


\section{References}

[1] C.S. Lee, D.K. Moser, T.A. Lennie, B. Riegel, Event-free survival in adults with heart failure who engage in self-care management, Heart Lung. 40 (2009) 12-20.

[2] H.G. Buck, C.S. Lee, D.K. Moser, N.M. Albert, T. Lennie, B. Bentley, et. al., Relationship between self-care and health-related quality of life in older adults with moderate to advanced heart failure, J. Cardiovasc. Nurs. 27 (2012) 8-15.

[3] J.R. Wu, D.J. Corley, T.A. Lennie, D.K. Moser, Effect of a medication-taking behavior feedback theory-based intervention on outcomes in patients with heart failure, J. Card. Fail. 18 (2012) 1-9.

[4] T. Jaarsma, A. Stromberg, J. Martensson, K. Dracup, A. Strömberg, J. Mårtensson, et al., Development and testing of the European Heart Failure Self-Care Behaviour Scale, Eur. J. Heart Fail. 5 (2003) 363-70.

[5] B. Riegel, C.S. Lee, V.V. Dickson, B. Carlson, An update on the self-care of heart failure index, J. Cardiovasc. Nurs. 24 (2009) 485-97.

[6] J. Cameron, L. Worrall-Carter, A. Driscoll, S. Stewart, Measuring self-care in chronic heart failure: a review of the psychometric properties of clinical instruments, J. Cardiovasc. Nurs. 24 (2009) E10-22.

[7] C. Baydemir, K. Özdamar, A. Ünalır, Validity of the Turkish version of the European Heart Failure Self-Care Behavior Scale, Anadolu Kardiyol. Derg. 13 (2013) 573-9.

[8] C. Shuldham, C. Theaker, T. Jaarsma, M.R. Cowie, Evaluation of the European Heart 
Failure Self-care Behaviour Scale in a United Kingdom population, J. Adv. Nurs. 60 (2007) 87-95.

[9] D.S.F. Yu, D.T.F. Lee, D.R. Thompson, T. Jaarsma, J. Woo, E.M.F. Leung, Psychometric properties of the Chinese version of the European Heart Failure Self-care Behaviour Scale, Int. J. Nurs. Stud. 48 (2011) 458-67.

[10] T. Jaarsma, K.F. Arestedt, J. Mårtensson, K. Dracup, A. Strömberg, The European Heart Failure Self-care Behaviour scale revised into a nine-item scale (EHFScB-9): a reliable and valid international instrument, Eur. J. Heart Fail. 11 (2009) 99-105.

[11] C.S. Lee, K.S. Lyons, J.M. Gelow, J.O. Mudd, S.O. Hiatt, T. Nguyen, et. al., Validity and reliability of the European Heart Failure Self-care Behavior Scale among adults from the United States with symptomatic heart failure, Eur. J. Cardiovasc. Nurs. 12 (2013) 214-8.

[12] S. Köberich, M. Glattacker, T. Jaarsma, C. Lohrmann, T. Dassen, S. Koberich, et al., Validity and reliability of the German version of the 9-item European Heart Failure Selfcare Behaviour Scale, Eur. J. Cardiovasc. Nurs. 12 (2013) 150-8.

[13] E. Vellone, T. Jaarsma, A. Strömberg, R. Fida, K. Årestedt, G. Rocco, et al., The European Heart Failure Self-care Behaviour Scale: new insights into factorial structure, reliability, precision and scoring procedure, Patient Educ. Couns. 94 (2014) 97-102.

[14] E. Lambrinou, F. Kalogirou, D. Lamnisos, E. Papathanassoglou, A. Protopapas, P. Sourtzi, et al., The Greek version of the 9-item European Heart Failure Self-care Behaviour Scale: a multidimensional or a uni-dimensional scale?, Heart Lung. 43 (2014) 494-9.

[15] D. Moher, L. Shamseer, M. Clarke, D. Ghersi, A. Liberati, M. Petticrew, et al., Preferred 
reporting items for systematic review and meta-analysis protocols (PRISMA-P) 2015 statement, Syst. Rev. 4 (2015) 1.

[16] M. Viswanathan, N.D. Berkman, D.M. Dryden, L. Hartling, Assessing risk of bias and confounding in observational studies of interventions or exposures: further development of the RTI item bank, Methods Res. Rep. 13-EHC106- (2013) 1-49.

[17] N. Kato, N. Ito, K. Kinugawa, K. Kazuma, Validity and reliability of the Japanese version of the European Heart Failure Self-Care Behavior Scale, Eur. J. Cardiovasc. Nurs. 7 (2008) 284-9.

[18] L. Hu, P.M. Bentler, Cutoff criteria for fit indexes in covariance structure analysis: Conventional criteria versus new alternatives, Struct. Equ. Model. A Multidiscip. J. 6 (1999) 1-55.

[19] L.K. Muthén, B.O. Muthén, Statistical analysis with latent variables, (16th ed.), Los Angeles, CA, 2001.

[20] L. Hu, P.M. Bentler, Structural equation modeling: concepts, issues, and applications, in: R.H. Hoyle (Ed.), Sage, Newbury Park, CA, 1995.

[21] D.J. Mundfrom, D.G. Shaw, T.L. Ke, Minimum Sample Size Recommendations for Conducting Factor Analyses. Int. J. Test. 5 (2009) 159-68.

[22] D.T. Campbell, D.W. Fiske, Convergent and discriminant validation by the multitraitmultimethod matrix, Psychol. Bull. 56 (1959) 81-105.

[23] J. Cohen, A power primer, Psychol. Bull. 112 (1992) 155-9. 
[24] J.R. Landis, G.G. Koch, The measurement of observer agreement for categorical data, Biometrics. 33 (1977) 159-74.

[25] J. Nunnally, I. Bernsterin, Psychometric Theory, 3rd ed, New York: McGraw Hill, 1994.

[26] M.K. Feijó, C.W. Ávila, E.N. de Souza, T. Jaarsma, E.R. Rabelo, M.K. Feijo, et al., Crosscultural adaptation and validation of the European Heart Failure Self-Care Behavior Scale for Brazilian Portuguese, Rev. Lat. Am. Enfermagem. 20 (2012) 988-96.

[27] G. Pulignano, D. Del Sindaco, G. Minardi, L. Tarantini, G. Cioffi, L. Bernardi, et al., Translation and validation of the Italian version of the European Heart Failure Self-care Behaviour Scale., J. Cardiovasc. Med.. 11 (2010) 493-8.

[28] I. Uchmanowicz, M. Loboz-Rudnicka, T. Jaarsma, K. Loboz-Grudzień, Cross-cultural adaptation and reliability testing of Polish adaptation of the European Heart Failure Selfcare Behavior Scale (EHFScBS), Patient Prefer. Adherence. 8 (2014) 1521-6.

[29] T. Jaarsma, Development and testing of the European Heart Failure Self-care Behaviour scale. https://www.isv.liu.se/medarbetare-vid-isv/jaarsma-tiny/scale/versions?l=sv/, (accessed 15.9.2016).

[30] W.F. Velicer, J.L. Fava, Affects of variable and subject sampling on factor pattern recovery, Psychol. Methods. 3 (1998) 231-51. 
Papers identified through hand searching, contacts with experts, follow up of reference $(n=2)$
Records identified through database searching

$$
(n=2154)
$$

Records after duplicate removal $(n=1431)$

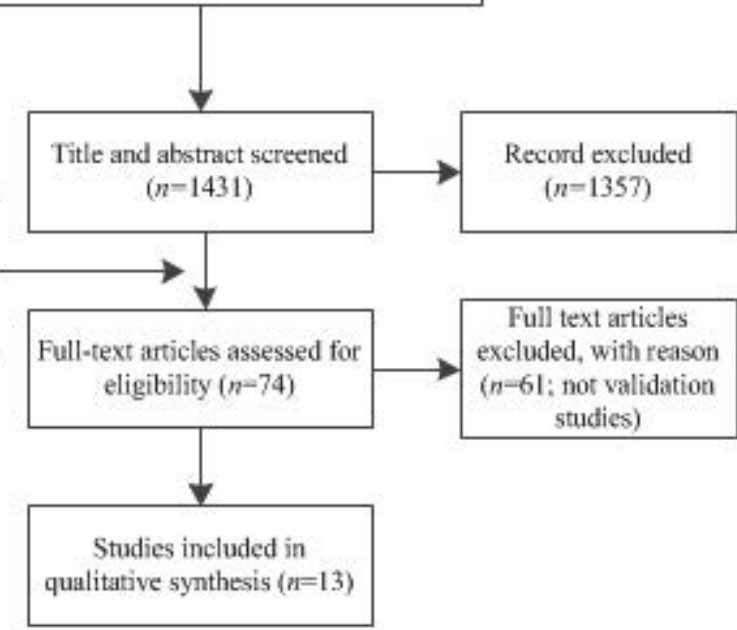




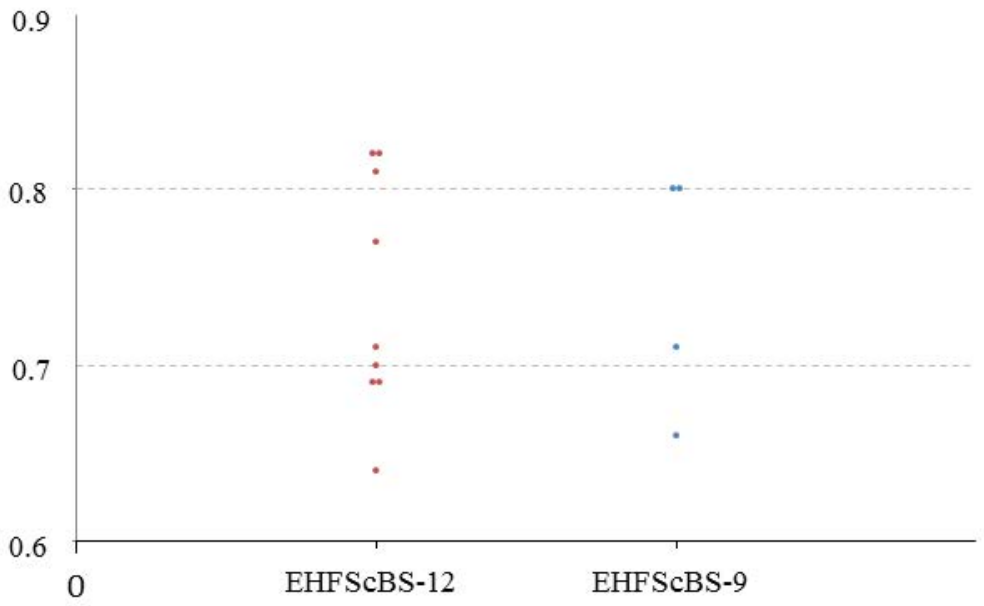


Figure legends

Figure 1. PRISMA flow diagram of study selection process.

Figure 2. Reliability coefficient (Cronbach's alpha) for the EHFScBS-12 and the EHFScBS-9. 


\section{Tables}

Table 1. Description of studies addressing psychometric properties of the EHFScBS-12 or the EHFScBS-9.

Table 2. Mean HF self-care behaviour score and items with lowest/highest scores.

Table 3. Validity and reliability of the EHFScBS-12.

Table 4. Validity and reliability of the EHFScBS-9. 
Table 1. Description of studies addressing psychometric properties of the EHFScBS-12 or the

\section{EHFScBS-9.}

\begin{tabular}{|c|c|c|c|c|c|c|c|c|}
\hline \multirow[t]{2}{*}{ Author/year } & \multicolumn{2}{|c|}{ Questionnaire } & \multicolumn{2}{|c|}{ Study design } & \multicolumn{4}{|l|}{ Participants } \\
\hline & Version & Language & $\begin{array}{l}\text { Sample } \\
\text { size }\end{array}$ & Setting & $\begin{array}{l}\text { Age, years } \\
(\text { mean } \pm S D)\end{array}$ & $\begin{array}{l}\text { Male } \\
(\%)\end{array}$ & NYHA & $\begin{array}{l}\text { LVEF, \% } \\
\text { (mean } \pm \text { SD) }\end{array}$ \\
\hline Baydemir et al. (2013)[7] & 12-item & Turkish & $n=494$ & $\begin{array}{l}\text { OPC, } \\
\text { Hosp }\end{array}$ & $\begin{array}{l}69.5 \pm 9.2 \\
\text { (female; } \\
n=223 \text { ) } \\
67.0 \pm 11.4 \\
\text { (male; } \\
n=271 \text { ) }\end{array}$ & 54.9 & I-IV & \\
\hline Feijó et al. (2012)[26] & 12-item & $\begin{array}{l}\text { Brazilian } \\
\text { Portuguese }\end{array}$ & $n=124$ & OPC & $62.3 \pm 12$ & 67 & & $33.6 \pm 10$ \\
\hline Jaarsma et al. (2003)[4] & 12-item & $\begin{array}{l}\text { Swedish } \\
\text { Dutch } \\
\text { Italian }\end{array}$ & $n=442$ & $\begin{array}{l}\text { PC, } \\
\text { Hosp, } \\
\text { OPC } \\
\text { Oth }\end{array}$ & $73 \pm 12$ & 58 & II-IV & \\
\hline Jaarsma et al. (2009)[10] & $\begin{array}{l}\text { 12-item/ } \\
\text { 9-item }\end{array}$ & $\begin{array}{l}\text { Swedish } \\
\text { Dutch } \\
\text { English } \\
\text { Italian } \\
\text { German } \\
\text { Spanish }\end{array}$ & $n=2592$ & $\begin{array}{l}\text { Hosp, } \\
\text { OPC }\end{array}$ & $71 \pm 12$ & 64 & I-IV & $34 \pm 14$ \\
\hline Kato et al. (2008)[17] & 12-item & Japanese & $n=116$ & OPC & $64.6 \pm 15.3$ & 70.7 & I-III & $54.1 \pm 14.0$ \\
\hline Köberich et al. (2013)[12] & 9-item & German & $n=109$ & $\begin{array}{l}\text { Hosp, } \\
\text { OPC }\end{array}$ & $62.5 \pm 11.9$ & 70.6 & I-IV & $\begin{array}{l}\mathrm{Me}(\mathrm{iqr})=25(2 \\
0-35)\end{array}$ \\
\hline $\begin{array}{l}\text { Lambrinou et al. } \\
\text { (2014)[14] }\end{array}$ & 9-item & Greek & $n=128$ & $\begin{array}{l}\text { Hosp. } \\
\text { OPC }\end{array}$ & $69.6 \pm 10.2$ & 78.1 & I-IV & $35.5 \pm 10.8$ \\
\hline Lee et al. (2013)[11] & 9-item & English & $n=200$ & OPC & $57.0 \pm 13.3$ & 50 & II-IV & $28.5 \pm 12.3$ \\
\hline $\begin{array}{l}\text { Pulignano et al. } \\
(2010)[27]\end{array}$ & 12-item & Italian & $n=93$ & OPC & $77 \pm 6$ & 47 & $\begin{array}{l}\mathrm{M} \pm \mathrm{SD}=2 . \\
8 \pm 0.6\end{array}$ & $31 \pm 11$ \\
\hline Shuldham et al. (2007)[8] & 12-item & English & $n=183$ & OPC & $65.6 \pm 12.3$ & 78.1 & I-IV & $46.8 \pm 14.7$ \\
\hline $\begin{array}{l}\text { Uchmanowicz et al. } \\
\text { (2014)[28] }\end{array}$ & 12-item & Polish & $n=100$ & OPC & $67.5 \pm 7.5$ & 67 & I-IV & $\begin{array}{l}\mathrm{Me}(\mathrm{iqr})=35(3 \\
0-45)\end{array}$ \\
\hline Vellone et al. (2014)[13] & 9-item & Italian & $n=1192$ & OPC & $72.4 \pm 11.2$ & 58.2 & I-IV & $44.7 \pm 10.8$ \\
\hline Yu et al. (2011)[9] & 12-item & Chinese & $n=143$ & $\mathrm{OPC}$ & $78.1 \pm 14.5$ & 37.8 & I-IV & \\
\hline
\end{tabular}

NYHA: New York Heart Association classification; LVEF: left ventricular ejection fraction; Hosp: hospital; OPC: Outpatient clinic; PC: primary care; Oth: other. 
Table 2. Mean HF self-care behaviour score and items with lowest/highest scores.

\begin{tabular}{|c|c|c|c|}
\hline Author/year & & & \\
\hline EHFScBS-12 & Mean score $(M)$ & $\begin{array}{l}\text { Item with lowest score } \\
(M \pm S D)\end{array}$ & $\begin{array}{l}\text { Item with highest score } \\
(M \pm S D)\end{array}$ \\
\hline Baydemir et al. (2013)[7] & $34.0 \pm 8.0$ & & \\
\hline Feijó et al. (2012)[26] & $24.7 \pm 8.5$ & $\begin{array}{l}\text { I take my medication } \\
\text { as prescribed }(1.0 \pm 0.3)\end{array}$ & $\begin{array}{l}\text { I weigh myself every } \\
\text { day }(3.6 \pm 1.5)\end{array}$ \\
\hline Jaarsma et al. (2003)[4] & $\begin{array}{l}n=140 \\
33.3 \pm 7.8 \text { (standard care) } \\
29.6 \pm 9.0 \text { (extra care) }\end{array}$ & $\begin{array}{l}\text { I take my medication } \\
\text { as prescribed }(1.2 \pm 0.9)\end{array}$ & $\begin{array}{l}\text { I exercise regularly } \\
(3.1 \pm 1.6) \text {; I weigh } \\
\text { myself every day } \\
(3.1 \pm 1.7)\end{array}$ \\
\hline Jaarsma et al. (2009)[10] & $\mathrm{Me}(\mathrm{iqr})=26(20-31)$ & $\begin{array}{l}\text { If I get short of breath I } \\
\text { take it easy; I take a } \\
\text { rest during the day; I } \\
\text { take my medication as } \\
\text { prescribed (Me=1(1- } \\
\text { 2)) }\end{array}$ & $\begin{array}{l}\text { I weigh myself every } \\
\text { day }(\mathrm{Me}=3(2-5)) ; \mathrm{I} \\
\text { exercise regularly } \\
(\mathrm{Me}=3(2-4))\end{array}$ \\
\hline Kato et al. (2008)[17] & $32.6 \pm 9.1$ & $\begin{array}{l}\text { I take my medication } \\
\text { as prescribed }(1.1 \pm 0.4)\end{array}$ & $\begin{array}{l}\text { I limit the amount of } \\
\text { fluids I drink }(3.6 \pm 1.7)\end{array}$ \\
\hline Pulignano et al. (2010)[27] & $24.3 \pm 6.7$ & $\begin{array}{l}\text { I take my medication } \\
\text { as prescribed }(1.3 \pm 0.6)\end{array}$ & $\begin{array}{l}\text { I exercise regularly } \\
(3.8 \pm 1.1)\end{array}$ \\
\hline Shuldham et al. (2007)[8] & $\mathrm{Me}(\mathrm{iqr})=31(24-36)$ & $\begin{array}{l}\text { I take my medication } \\
\text { as prescribed (1.2) }\end{array}$ & $\begin{array}{l}\text { If I gain } 5 \mathrm{lb} \text { in one } \\
\text { week, I contact my } \\
\text { doctor or nurse (3.5) }\end{array}$ \\
\hline $\begin{array}{l}\text { Uchmanowicz et al. } \\
\text { (2014)[28] }\end{array}$ & $34.2 \pm 8.1$ & $\begin{array}{l}\text { I take my medication } \\
\text { as prescribed } \\
(1.6 \pm 1.3) \text {; If I get short } \\
\text { of breath I take it easy } \\
(1.6 \pm 1.2)\end{array}$ & 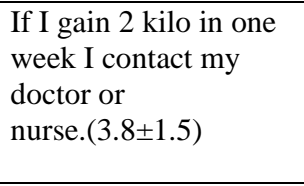 \\
\hline Yu et al. (2011)[9] & $28.6 \pm 4.2$ & & \\
\hline EHFScBS-9 & Mean score $(M)$ & $\begin{array}{l}\text { Item with lowest score } \\
(M \pm S D)\end{array}$ & $\begin{array}{l}\text { Item with highest score } \\
(M)\end{array}$ \\
\hline Jaarsma et al. (2009)[10] & & $\begin{array}{l}\text { I take my medication } \\
\text { as prescribed }(\mathrm{Me}=1(1- \\
2))\end{array}$ & $\begin{array}{l}\text { I weigh myself every } \\
\text { day }(\mathrm{Me}=3(2-5)) ; \mathrm{I} \\
\text { exercise regularly } \\
(\mathrm{Me}=3(2-4))\end{array}$ \\
\hline Köberich et al. (2013)[12] & $19.9 \pm 6.5$ & $\begin{array}{l}\text { I take my medication } \\
\text { as prescribed }(1.2 \pm 0.6)\end{array}$ & $\begin{array}{l}\text { I eat a low-salt diet } \\
(2.9 \pm 1.4)\end{array}$ \\
\hline Lambrinou et al. (2014)[14] & & $\begin{array}{l}\text { I take my medication } \\
\text { as prescribed }(1.1 \pm 0.6)\end{array}$ & $\begin{array}{l}\text { I limit the amount of } \\
\text { fluids I drink }(3.9 \pm 1.6)\end{array}$ \\
\hline Lee et al. (2013)[11] & $18.1 \pm 6.8$ & $\begin{array}{l}\text { I take my medication } \\
\text { as prescribed }(1.1 \pm 0.4)\end{array}$ & $\begin{array}{l}\text { I exercise regularly } \\
(2.9 \pm 1.4)\end{array}$ \\
\hline Vellone et al. (2014)[13] & $23.9 \pm 6.9$ & $\begin{array}{l}\text { I take my medication } \\
\text { as prescribed }(\mathrm{Me}=1(1- \\
2))\end{array}$ & $\begin{array}{l}\text { If I gain } 5 \text { lb in one } \\
\text { week, I contact my } \\
\text { doctor or nurse } \\
(\mathrm{Me}=3(2-5))\end{array}$ \\
\hline
\end{tabular}

Note: Lower scores indicate better self-care; possible scores on the EHFScBS-12 range from 12 to 60; possible scores on the EHFScBS-9 range from 9 to 45 . 
Table 3. Validity and reliability of the EHFScBS-12.

\begin{tabular}{|c|c|c|c|c|c|}
\hline \multirow{3}{*}{$\begin{array}{l}\text { EHFScBS12 } \\
\text { Author/year }\end{array}$} & \multirow{2}{*}{\multicolumn{2}{|c|}{ Validity }} & \multicolumn{3}{|l|}{ Reliability } \\
\hline & & & \multirow{2}{*}{$\begin{array}{l}\text { Stability } \\
\text { Test-retest }\end{array}$} & \multicolumn{2}{|l|}{ Homogenity } \\
\hline & Construct validity & Criterion validity/Contrasted groups & & $\begin{array}{l}\text { Corrected } \\
\text { item-total } \\
\text { correlations }\end{array}$ & $\begin{array}{l}\text { Internal consistency } \\
\text { (Cronbach's } \alpha \text { ) }\end{array}$ \\
\hline $\begin{array}{l}\text { Baydemir et } \\
\text { al. (2013)[7] }\end{array}$ & $\begin{array}{l}\text { PCA (varimax rotation) explained variance: } \\
\text { 61\%, } 4 \text { components } \\
\text { CFA: } 4 \text { factors } \\
\text { RMSEA }=0.05 \text {, CI(0.00-0.08); } \\
\text { GFI }=0.91 ; \text { AGFI }=0.83 \\
\text { F1: compliance to the treatment } \\
\text { F2: adherence to the activities } \\
\text { F3: adherence to the recommendations } \\
\text { F4: getting help }\end{array}$ & & & $\begin{array}{l}\text { Range: }-0.16 \\
\text { to } 0.57\end{array}$ & $\begin{array}{l}\text { Total scale: } \\
0.69 \text {. } \\
\text { Subscale 1: } 0.79 \\
\text { Subscale 2: } 0.69 \\
\text { Subscale 3: } 0.12 \\
\text { Subscale 4: } 0.28\end{array}$ \\
\hline $\begin{array}{l}\text { Feijó et al. } \\
\text { (2012)[26] }\end{array}$ & & & ICC $=0.87(N=24)$ & $\begin{array}{l}\text { Range: } 0.13 \text { to } \\
0.58\end{array}$ & $\begin{array}{l}\text { Total scale: } \\
0.7 \\
\end{array}$ \\
\hline $\begin{array}{l}\text { Jaarsma et al. } \\
\text { (2003)[4] }\end{array}$ & $\begin{array}{l}\text { PCA (varimax rotation) partially confirmed } \\
\text { the } 3 \text { hypothetisized dimensions - several } \\
\text { items loaded on more than } 1 \text { factor ( } 4 \text { items } \\
\text { regarding contacting a health care } \\
\text { professional loaded on one component) }\end{array}$ & $\begin{array}{l}\text { Contrasted groups }(N=140) \text { : non-significant } \\
\text { better self-care }(t=2.6, p=0.09) \text { in patients } \\
\text { with extra care }(M=29.6 \pm 9.0) \text { than patients } \\
\text { with standard care }(M=33.3 \pm 7.8)\end{array}$ & & $\begin{array}{l}\text { Range: } 0.40 \text { to } \\
0.74\end{array}$ & $\begin{array}{l}\text { Total scale: } 0.81 . \\
\text { During follow up: T1-3 } \\
\text { months (Sweden } \\
N=114 \text { ): } 0.71 \text {; } \\
\text { T2-12 months (Sweden } \\
N=120 \text { ): } 0.69\end{array}$ \\
\hline $\begin{array}{l}\text { Jaarsma et al. } \\
\text { (2009)[10] }\end{array}$ & $\begin{array}{l}\text { CFA: } 1 \text { factor vs } 3 \text { factors } \\
\text { F1:adherence to regimen } \\
\text { F2 asking for help } \\
\text { F3 adapting activities } \\
\chi 2(54)=612.9, p<0.001 / \chi 2(51)=554.0, p< \\
0.001 ; \text { RMSEA }=0.06,90 \% \text { CI }(0.06-0.07) ; \\
\text { CFI=0.64/0.68; NFI }=0.62 / 0.66 \text {; GFI }=0.94 \text {; } \\
\text { AGFI }=0.91 / 0.92 ;\end{array}$ & $\begin{array}{l}\text { Convergent validity: questionnaire vs } \\
\text { revised HF Compliance Questionnaire } \\
(r=0.32, p<0.001) \\
\text { Discriminant validity: questionnaire vs } \\
\text { MLwHFQ }(r=0.01 \text {, NS })\end{array}$ & & $\begin{array}{l}\text { Range: } 0.14 \text { to } \\
0.65\end{array}$ & Total scale: 0.77 \\
\hline $\begin{array}{l}\text { Kato et al. } \\
\text { (2008)[17] }\end{array}$ & $\begin{array}{l}\text { CFA: } 1 \text { factor } \\
\text { RMSEA }=0.08 ; \text { CFI }=0.85 ; \text { GFI }=0.87 \text {; } \\
\text { AGFI }=0.82\end{array}$ & $\begin{array}{l}\text { Convergent validity: questionnaire vs } \\
\text { subscale of the SCAQ }(r=-0.29, p<0.05)\end{array}$ & $\begin{array}{l}\text { ICC }=0.69(N=95) \\
\text { Items (weighted } \\
\text { Kappa coefficient: } \\
\text { 0.33-0.87) }\end{array}$ & & Total scale: 0.71 \\
\hline $\begin{array}{l}\text { Pulignano et } \\
\text { al. (2010)[27] }\end{array}$ & & $\begin{array}{l}\text { Contrasted groups: significant better self- } \\
\text { care }(p<0.001) \text { in patients already followed } \\
\text { in the HFC (previously received structured } \\
\text { HF education) }(N=54 ; M=20.9 \pm 4) \text { than in } \\
\text { patients evaluated at baseline visit before } \\
\text { enrolment in the HFC }(N=39 ; M=28.9 \pm 6)\end{array}$ & & $\begin{array}{l}\text { Range: }-0.92 \\
\text { to } 0.90\end{array}$ & Total scale: 0.82 \\
\hline
\end{tabular}




\begin{tabular}{|c|c|c|c|c|c|}
\hline $\begin{array}{l}\text { Uchmanowic } \\
\mathrm{z} \text { et al. } \\
\text { (2014)[28] }\end{array}$ & & & & $\begin{array}{l}\text { Range } 0.03 \text { to } \\
0.59\end{array}$ & Total scale: 0.64 \\
\hline $\begin{array}{l}\text { Yu et al. } \\
\text { (2011)[9] }\end{array}$ & $\begin{array}{l}\text { CFA: } 3 \text { factors } \\
\text { F1: comply with regimen } \\
\text { F2: adapting activity } \\
\text { F3: help seeking } \\
\text { only some fit statistics support the structure } \\
\chi 2 \text { /df = } 60.43 / 51=1.18 ; \text { RMSEA }=0.04 ; \\
\text { CFI=0.80; GFI }=0.85 ; \text { AGFI }=0.77 \\
\text { PCA (direct oblimin rotation), } 2 \\
\text { components, explained variance: } 31.2 \% \\
\text { C1: regimen-complying behaviours } \\
\text { C2: help-seeking }\end{array}$ & & & $\begin{array}{l}\text { Range: } 0.23 \text { to } \\
0.50\end{array}$ & $\begin{array}{l}\text { Total scale } 0.82 \\
\text { F1: } 0.68 \\
\text { F2: } 0.41 \\
\text { F3: } 0.72\end{array}$ \\
\hline
\end{tabular}

PCA: principal component analysis; CFA: confirmatory factor analysis; RMSEA: root-mean-square error of approximation; CFI: comparative fit index; NFI: normed fit index; GFI: goodness-of-fit index; AGFI: adjusted goodness-of-fit index; F: factor; ICC: intraclass correlation coefficient; MLwHFQ: Minnesota Living with Heart Failure Questionnaire; SCAQ: Self-Care Agency Questionnaire; KCCQ: Kansas City Cardiomyopathy Questionnaire; SCHFI: Self-Care of Heart Failure Index; SD: standard deviation. 
Table 4. Validity and reliability of the EHFScBS-9.

\begin{tabular}{|c|c|c|c|c|c|}
\hline \multirow{3}{*}{$\begin{array}{l}\text { EHFScBS9 } \\
\text { Author/year }\end{array}$} & \multirow{2}{*}{\multicolumn{2}{|c|}{ Validity }} & \multicolumn{3}{|l|}{ Reliability } \\
\hline & & & \multirow{2}{*}{$\begin{array}{l}\text { Stability } \\
\text { Test-retest }\end{array}$} & \multicolumn{2}{|l|}{ Homogenity } \\
\hline & Construct validity & Criterion validity/Contrasted groups & & $\begin{array}{l}\text { Corrected } \\
\text { item-total } \\
\text { correlations } \\
\end{array}$ & $\begin{array}{l}\text { Internal consistency } \\
\text { (Cronbach's } \alpha \text { ) }\end{array}$ \\
\hline $\begin{array}{l}\text { Jaarsma et al. } \\
\text { (2009)[10] }\end{array}$ & $\begin{array}{l}\text { CFA: } 1 \text { factor vs } 2 \text { factors } \\
\text { F1: consulting behaviour } \\
\text { F2: adherence to regimen } \\
\chi 2(27)=325.2, p<0.001 / \chi 2(26)=275.4 \text {, } \\
p<0.001 \text {; RMSEA }=0.06 / 0.07,90 \% \text { CI }(0.06- \\
0.07) \text {; CFI }=0.77 / 0.81 ; \text { NFI }=0.76 / 0.79 \text {; } \\
\text { GFI }=0.96 / 0.97 ; \text { AGFI }=0.94\end{array}$ & $\begin{array}{l}\text { Convergent validity: questionnaire vs } \\
\text { revised HF Compliance Questionnaire } \\
(r=0.37, p<0.001) \\
\text { Discriminant validity: questionnaire vs } \\
\text { MLwHFQ ( } r=0.18, N S)\end{array}$ & & $\begin{array}{l}\text { Range: } 0.28 \text { to } \\
0.68\end{array}$ & $\begin{array}{l}\text { Total scale: } 0.80 \\
\text { Subscale 1: } 0.85 \\
\text { Subscale 2: } 0.56\end{array}$ \\
\hline $\begin{array}{l}\text { Köberich et } \\
\text { al. (2013)[12] }\end{array}$ & $\begin{array}{l}\text { PCA (varimax rotation) explained variance } \\
\text { (\%): } 62.6,3 \text { factors } \\
\text { Analysis of item loadings shows that only } \\
\text { one subscale can be distinguished (asking } \\
\text { for help) }\end{array}$ & $\begin{array}{l}\text { Discriminant validity: questionnaire vs } \\
\text { KCCQ }(r=0.10 ; p=0.32) \\
\text { Contrasted groups: significant better self- } \\
\text { care }(t=2.11, p=0.04) \text { in patients with extra } \\
\text { care }(N=19 ; M=16.7 \pm 6.5) \text { than patients with } \\
\text { standard care }(N=90 ; M=20.1 \pm 6.4)\end{array}$ & $\begin{array}{l}\text { ICC }=0.69 ; 95 \% \text { CI: } \\
0.56-0.79(N=87) \\
\text { Items }(0.40-0.87)\end{array}$ & $\begin{array}{l}\text { Range: } 0.09 \text { to } \\
0.63\end{array}$ & $\begin{array}{l}\text { Total scale: } 0.71(95 \% \\
\text { CI: } 0.63-0.77)\end{array}$ \\
\hline $\begin{array}{l}\text { Lambrinou et } \\
\text { al. (2014)[14] }\end{array}$ & 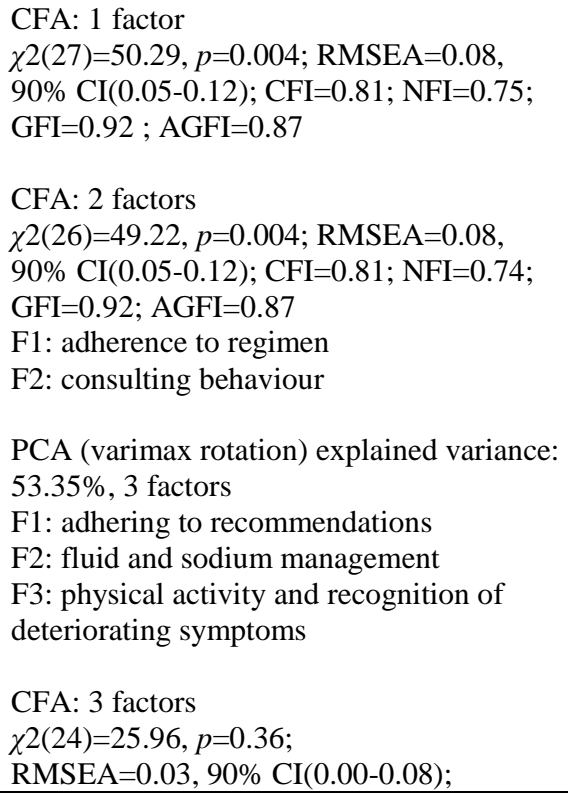 & $\begin{array}{l}\text { Discriminant validity: questionnaire vs } \\
\text { MLwHFQ }(r=-0.02, p=0.83)\end{array}$ & & & $\begin{array}{l}\text { Total scale: } 0.66 \\
\text { Subscale 1: } 0.57 \\
\text { Subscale 2: } 0.54 \\
\text { Subscale 3: } 0.51\end{array}$ \\
\hline
\end{tabular}




\begin{tabular}{|c|c|c|c|c|}
\hline & $\begin{array}{l}\text { CFI } 0.98, \mathrm{NFI}=0.98 ; \mathrm{GFI}=0.96 \text {; } \\
\text { AGFI }=0.92\end{array}$ & & & \\
\hline $\begin{array}{l}\text { Lee et al. } \\
\text { (2013)[11] }\end{array}$ & $\begin{array}{l}\text { CFA: } 1 \text { factor } \\
\chi 2(27)=103, p<0.001 ; \\
\text { RMSEA=0.12, 90\% CI( } 0.09-0.14) \text {; } \\
\text { CFI }=0.94 ; \text { NFI }=0.92 ; \text { TLI=0.92; } \\
\text { WRMR=1.00; AGFI }=0.90 \\
\\
\text { CFA: Factor consulting behavior } \\
\chi 2(2)=9.54, p=0.008 ; \text { RMSEA }=0.14,90 \% \\
\text { CI( } 0.03-0.20) ; \text { CFI }=0.99 ; \text { NFI }=0.99 ; \\
\text { TLI }=0.98 ; \text { WRMR }=0.40 ; \text { AGFI }=0.97\end{array}$ & $\begin{array}{l}\text { Convergent validity: Questionnaire vs } \\
\text { SCHFI Maintainance and SCHFI } \\
\text { Management ( } r=-0.59 ; r=-0.42 ; p<0.01) \\
\\
\text { Discriminant validity: Questionnaire vs } \\
\text { MLHFQ Physical, Emotional }(r=0.13 \text {; } \\
r=0.16 \text {; NS) }\end{array}$ & $\begin{array}{l}\text { Range } 0.25 \text { to } \\
0.65\end{array}$ & $\begin{array}{l}\text { Total scale: } \\
0.80 \text { ( } 95 \% \mathrm{CI}=0.76- \\
0.84) \\
\\
\text { Subscale consulting } \\
\text { behaviour: } 0.85 \\
(95 \% \text { CI }=0.81-0.88)\end{array}$ \\
\hline
\end{tabular}

PCA: principal component analysis; CFA: confirmatory factor analysis; RMSEA: root-mean-square error of approximation; ; CFI: comparative fit index; NFI: normed fit index; NNFI (TLI): non-normed fit index (Tucker-Lewis index); SRMR: standardized root mean square residual; WRMR: weighted root mean square residual; GFI: goodness-of-fit index; AGFI: adjusted goodness-of-fit index; CI: confidence interval; F: factor; ICC: intraclass correlation coefficient; MLwHFQ: Minnesota Living with Heart Failure Questionnaire; SCAQ: Self-Care Agency Questionnaire; KCCQ: Kansas City Cardiomyopathy Questionnaire; MMSE score: Mini-Mental State Examination; SCHFI: Self-Care of Heart Failure Index; SEM: standard error of measurement; SDR: smallest real difference; SD: standard deviation. 
Appendix. Bias analysis

Table I. Bias assessment of included studies.

\begin{tabular}{|c|c|c|c|c|c|c|c|c|c|c|c|c|c|c|c|}
\hline & & & 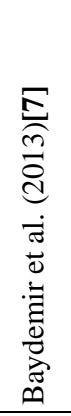 & 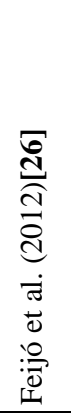 & 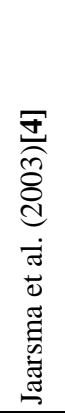 & 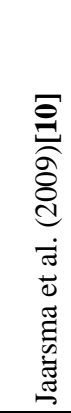 & 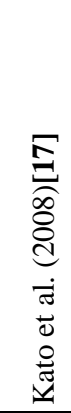 & 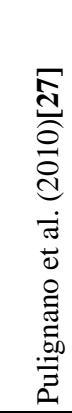 & 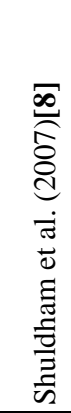 & 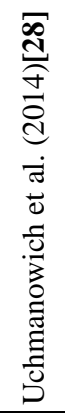 & 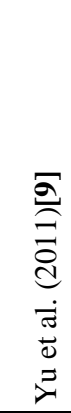 & 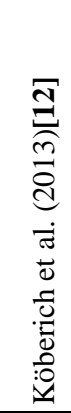 & 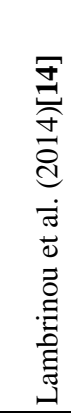 & 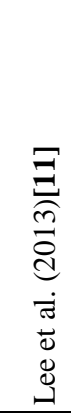 & 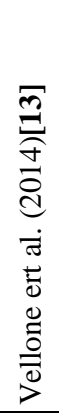 \\
\hline & & Questions to assess the risk of bias & & & & & & & & & & & & & \\
\hline$S$ & Q1 & $\begin{array}{l}\text { Do the inclusion/exclusion criteria vary across the } \\
\text { comparison groups (the individuals) of the study? }\end{array}$ & $\mathrm{N}$ & $\mathrm{N}$ & $\mathrm{U}$ & $\mathrm{U}$ & $\mathrm{N}$ & $\mathrm{U}$ & $\mathrm{N}$ & $\mathrm{N}$ & $\mathrm{N}$ & $\mathrm{N}$ & $\mathrm{N}$ & $\mathrm{N}$ & $\mathrm{N}$ \\
\hline S, C & Q2 & $\begin{array}{l}\text { Does the strategy for recruiting participants into the study } \\
\text { differ across groups (individuals)? }\end{array}$ & $\mathrm{N}$ & $\mathrm{N}$ & U & U & $\mathrm{N}$ & $\mathrm{U}$ & $\mathrm{N}$ & $\mathrm{N}$ & $\mathrm{N}$ & $\mathrm{N}$ & $\mathrm{N}$ & $\mathrm{U}$ & $\mathrm{U}$ \\
\hline $\mathrm{S}, \mathrm{C}$ & Q3 & $\begin{array}{l}\text { Is the selection of the comparison group inappropriate, after } \\
\text { taking into account feasibility and ethical considerations? }\end{array}$ & NA & NA & NA & NA & NA & NA & NA & NA & NA & NA & NA & NA & NA \\
\hline $\mathrm{P}$ & Q4 & $\begin{array}{l}\text { Does the study fail to account for variations in the execution } \\
\text { of the study from the proposed protocol? }\end{array}$ & $\mathrm{N}$ & $\mathrm{N}$ & $\mathrm{U}$ & $\mathrm{U}$ & $\mathrm{N}$ & $\mathrm{N}$ & $\mathrm{N}$ & $\mathrm{N}$ & $\mathrm{N}$ & $\mathrm{N}$ & $\mathrm{N}$ & $\mathrm{N}$ & $\mathrm{N}$ \\
\hline $\mathrm{D}, \mathrm{C}$ & Q6 & $\begin{array}{l}\text { Were valid and reliable measures, implemented consistently } \\
\text { across all study participants used to assess } \\
\text { inclusion/exclusion criteria, intervention/exposure outcomes, } \\
\text { participant health benefits and harms, and confounding?a }\end{array}$ & $\mathrm{Y}$ & $\mathrm{Y}$ & $\mathrm{Y}$ & $\mathrm{Y}$ & $\mathrm{Y}$ & $\mathrm{Y}$ & $\mathrm{Y}$ & $\mathrm{Y}$ & $\mathrm{Y}$ & $\mathrm{Y}$ & $\mathrm{Y}$ & $\mathrm{Y}$ & $\mathrm{Y}$ \\
\hline $\mathrm{R}$ & Q9 & $\begin{array}{l}\text { Are any important primary outcomes missing from the } \\
\text { results? }\end{array}$ & $\mathrm{N}$ & $\mathrm{N}$ & $\mathrm{N}$ & $\mathrm{N}$ & $\mathrm{N}$ & $\mathrm{N}$ & $\mathrm{N}$ & $\mathrm{N}$ & $\mathrm{N}$ & $\mathrm{N}$ & $\mathrm{N}$ & $\mathrm{N}$ & $\mathrm{N}$ \\
\hline \multirow[t]{2}{*}{$\begin{array}{l}\text { over } \\
\text { all }\end{array}$} & Q11 & $\begin{array}{l}\text { Are results believable taking study limitations into } \\
\text { consideration? }\end{array}$ & $\mathrm{Y}$ & $\mathrm{Y}$ & $\mathrm{P}$ & $\mathrm{P}$ & $\mathrm{Y}$ & $\mathrm{P}$ & $\mathrm{Y}$ & $\mathrm{Y}$ & $\mathrm{Y}$ & $\mathrm{Y}$ & $\mathrm{Y}$ & $\mathrm{Y}$ & $\mathrm{Y}$ \\
\hline & & Questions to assess precision & & & & & & & & & & & & & \\
\hline $\mathrm{P}$ & Q15 & $\begin{array}{l}\text { Are the statistical methods used to assess the primary benefit } \\
\text { outcomes (psychometric characteristics of the questionnaire) } \\
\text { inadequate? }\end{array}$ & $\mathrm{N}$ & $\mathrm{P}$ & $\mathrm{N}$ & $\mathrm{N}$ & $\mathrm{N}$ & $\mathrm{N}$ & $\mathrm{N}$ & $\mathrm{P}$ & $\mathrm{N}$ & $\mathrm{N}$ & $\mathrm{N}$ & $\mathrm{N}$ & $\mathrm{N}$ \\
\hline
\end{tabular}

${ }^{a}$ Confounding variables were not included because the aim of the study was validation of the questionnaire

N: no; Y: yes; P: partially; U: unclear; N/A: not applicable; S: selection bias; P: performance bias; D: detection bias; R: selective outcome reporting; C: confounding; P: precision 